\title{
Linguistic Features of Typographic Emoticons in SMS Discourse
}

\author{
Natia Amaghlobeli \\ Faculty of the school of graduate studies, Ilia State University, Tbilisi, Georgia \\ Email: natiama2000@yahoo.fr
}

\begin{abstract}
With the flourishing of information technology in the last 50 years, electronic communication has become a significant part of our daily lives. As electronic language is written text, it is divorced from gestures, facial expressions, and prosodic features such as intonation, rhythm, and volume. That is why emoticons have entered cyberspace; they infuse electronic communication with an emotional, human touch. This paper deals with typographic emoticons as linguistic units, and observes their structures and uses in sentences. The research corpus covers 258 French text messages collected with anonym questionnaire around the years 2008 2009. After a graphic analysis of typographic emoticons, we define "emoticon structure" as "a pictogram-like unit formed with alphagrams and topograms of distinctive significative function, and visually conditioned to the referent". Morphological analysis has shown that, in emoticon structure, graphemes of entirely different significances and functions become morpheme-like units, which, like word morphemes, can be derivational, inflectional, or abbreviated, but never unbound. Relying on a corpus, we isolated the two main uses of the emoticon: non-verbal and verbal. The former is the more frequent use, so it is considered in more detail in this paper. Analysis has shown that emoticons are not only paraverbal devices, but also structural markers, and they play a significant role in the formation of the sentence.
\end{abstract}

Index Terms - emoticon, smiley, sms language, paraverbal, morphological analysis

\section{INTRODUCTION}

With the flourishing of information technology in the last 50 years, electronic communication has become a significant part of our daily lives. As electronic language is written text, it is divorced from gestures, facial expressions, and prosodic features such as intonation, rhythm, and volume. These features naturally led to the difficulty of comfortable and smooth communication, as it is known that the contribution of the purely linguistic elements in our actual face-to-face communication is much smaller than non-verbal information and prosodic features (Mehrabian, 1971). That is why emoticons (or smileys) have entered cyberspace to provide the electronic communication with emotional and human touch. An emoticon (word from emotion and icon) is a facial expression represented by a combination of punctuation mark, letters or other characters, that viewed from the side resembles a facial expression or, more rarely, gestures. Today some software, such as Microsoft Word or email client programs, automatically convert typographic emoticons into graphic ones, that are more expressive, often animated and represent images in Gif format.

The Hacker's Dictionary (Raymond, 1994) provides a section on the origins and proper use of emoticons, as well as its generally accepted definition:"An ASCII glyph is used to indicate an emotional state in e- mail or news". Sanderson defined "smileys" as "a sequence of ordinary characters you can find on your computer keyboard. Smileys are used in e-mail and other forms of communication using computers" (Sanderson, 1993, p. 1). For Rezabek and Cochenour emoticons are "visual cues formed from ordinary typographical symbols that when read sideways represent feelings or emotions" (Rezabek and Cochenour,1998, p. 201). Godin agreed that "until the advent of the smiley, otherwise known as an emoticon, individuals using electronic communication had no way to indicate the subtle mood changes. They couldn't tell jokes, use irony, slip in a pun or become bitingly sarcastic" (Godin,1993, p. 4). According to Marvin "these symbols are the paralanguage of the internet" (Marvin,1995).

The first smiley face, which represents eyes, a nose and a smiling mouth, was invented in 1982 by Scott Fahlman, research professor specialized in artificial intelligence at Carnegie Melon School of Computer Science. Smiley faces become more and more popular among Internet and SMS users, despite some researchers such as Andrews claiming that "emoticons waste bandwidth, have inconsistent definitions and are superfluous, a well-constructed sentence needs no clarification and emoticons serve no purpose" (Andrews, 1994).

The field of emoticon study has a long tradition and was observed from different perspectives with a focus on specific objectives. Some research in psychology has focused on the emotional dimension of emoticons and their role in message interpretation (Walther \& D'Addario, 2001). Emoticons are also considered as politeness indicators (Bunz \& Campbell, 2004). The feasibility of emoticons as answer categories for questions aiming at emotional states and feelings has also been investigated (Meschtscherjakov, Weiss \& Scherndl, 2009). In particular, Riva analyzed emoticons with relation to socio-cognitive processes of emotional expression. 
Gender differences in the use of emoticons are frequently examined (Witmer \& Katzman, 1997; Fullwood \& Martino, 2007). Huffaker and Calvert (2005) for example suggest that teenage girls use emoticons less frequently than teenage boys. Drawing on the current literature, Witmer and Katzman (1997) on the other hand found evidence to suggest that women use more emoticons than men in Computer Mediated Communication. The use of emoticons in communication may be influenced to some extent by the sex of the partner with whom one is interacting. Indeed, Wolf (2000) found that when males are communicating with females they tend to adopt the female standard of expressing more emotion. Wolf (2000) also noted that men and women used emoticons for different purposes. Men tended to use emoticons in a sarcastic or teasing manner, whereas women tended to uses emoticons more often when they were attempting to communicate humorous messages.

Studies about emoticons' place within the speaking-writing dichotomy are also numerous. Most often, emoticons are represented as conventions used to compensate for the absence of paralinguistic indicators, such as mimogestuality or intonation (Baron, 2000; Kruger, Epleye, Parker, \& NG, 2005; Marcoccia, 2000). Mourhlon-Dallies and Collin (1994) compare smileys to the system of stage directions in theatrical texts, as they allow the reader to recreate absent reality and corporality while reading the text.

Linguistic studies of emoticon offer their semantic and syntactic descriptions (Bodi \& Veszelszki, 2006), thematic and functional classification (Bodi \& Veszelszki, 2006; Marcoccia \& Gauducheau, 2007). The visual aspects of emoticons are also examined (Herring, 2001).

Studies of emoticons from pedagogical perspective are also interesting. Azuma and Ebner have proposed the implementation of a universal auxiliary language based on the use of emoticons and its possible educational applications (2008).

\section{RESEARCH OBJECT AND CORPUS}

The research corpus covers 258 French text messages collected with anonym questionnaire around the years 2008 2009. After providing their age (17 to 35 year), gender and profession informants were asked to copy 3 or 5 SMS from their mobile phones into the questionnaires. The questionnaires with special cover letter were sent via e-mail to the addresses collected in social sites. We have moved from the corpus publicity messages, SMS containing only non-letter characters and messages written on the computer.

In general three types of emoticon can be found in electronic communication:

1. Typographic emoticons - :-) - formed with punctuation marks or other typographic symbols that can be found on the computer keyboard or mobile phone's keypad.

2. Graphic emoticons - :- - often animated, represent images in Gif format. As said before, some software automatically converts typographic emoticons into graphic ones.

3. Verbal emoticons ('Happy Smiley') verbally represent graphic or typographic ones and become more and more productive, parallel with the classical, non-verbal smileys. In this case, we observe the reverse process of imitation of graphic symbol by linguistic means. It is a new and interesting type of emoticon that can be studied separately. This type of emoticons cannot be found only in internet communication.

In our paper we will discuss typographic emoticons, their structure and use in sms discourse.

\section{DISCUSSION}

\section{A. Structure}

Emoticons consist of two, three, or four graphems corresponding to the zones of the human face described by Ekman $^{1}$. Semantically more changed and thus more variable are the eyes and the mouth. Two other zones, the nose and eyebrows, can be added or omitted. In addition to these four basic graphems, emoticons may include additional zones, such as tears, hair, saliva, teeth, tongue, etc.

The eyes are often encoded by a colon, but they can also be found as a semicolon, equal sign $(=)$, the numeral eight (8), the letter B, a percent sign (\%), etc. All of these characters represent varying degrees of openness of the eye and consequently, in combination with other characters of the face, they encode a variety of emotional nuances. The mouth is denoted traditionally by the bracket (to encode a spread of emotions from sadness to joy), but different meanings may be indicated by letters, typographic characters, numerals, and other characters. The nose rarely changes the meaning of an emoticon, except in the case of mischief or tomfoolery, so it is traditionally denoted by a hyphen.

As it is known, the sign that conveys its meaning through its pictorial resemblance to a physical object is a pictogram. Thus, emoticons can be viewed as pictograms formed with graphemes - the smallest units of the graphic form defined by their function in written communication (Anis, 1988).

Anis delineates three classes of graphems:

\footnotetext{
${ }^{1}$ Paul Ekman, Professor of psychology at the University of California, is recognized as a world expert in the study of emotions, including their nonverbal facial expressions. He recorded that the majority of facial expressions and their corresponding emotions are not because of culture, but derive from human biology. He considers six basic emotions to be universal: happiness, sadness, anger, fear, disgust, and surprise.

A principle of Ekman's study of emotions is that the face is divided into three horizontal areas: brow / forehead, eyes, and lids / root of nose and the lower face, including the cheeks, mouth, most of the nose, and chin. Their juxtaposition allows recognition of the six basic emotions (Ekman, 1977).
} 
1. Alphabetic graphems (or alphagrams): purely distinctive units constituting the heart of graphic systems;

2. Ponctuo-typographical graphems (or topograms): distinctive, significative units [parallel] to the syntagmatic and enunciative structuring of the graphic chain;

3. Logogrammatical graphems (or logograms): unique graphems corresponding to a significant unit or group with a synthetic function (acronyms, logos) (Anis, 1998: 15).

From these three classes of graphemes, we can easily observe that emoticons more frequently contain alphagrams and topograms (logograms are extremely rare), although, according to Anis, alphagrams are only segmental units; in the structure of emoticons, they have their own significance. For example, in picture 1 the final graphem (P) is an alphabetic representation of an extended tongue. In the same emoticon, standard graphemes are used with non-standard significance.

\section{$:-\mathrm{P}$ \\ Picture 1}

Pierozak (2003) compares the graphemes of emoticons to word morphemes and underlines the arbitrary relationship between the signifier and signified. But as emoticons in their structure are pictograms, thus conveying their meaning through their pictorial resemblance to physical objects, the relation between signified and signifier cannot be arbitrary. Each grapheme in emoticons is visually conditioned.

Thus, we can define the structure of emoticons as follows: Emoticons are pictogram-like units formed with alphagrams and topograms of distinctive significative function, and visually conditioned to the referent.

If, as Pierozak (2003) suggests, we define graphemes of emoticons as morphemes, then we can say that they are lexical morphemes that have a completely different significance when standing alone. For example, in picture 2 the bracket represents the mouth, but when standing alone, it is a punctuation mark. Thus the sign ")" as a grapheme is free, but as a morpheme in the structure of an emoticon, it is bound. The process of reduplication in the structure of emoticons is also interesting. It is expressed in the repetition of the right (lower) part of the emoticon and serves to reinforce the emotions. In this case, this part of the emoticon can be treated as an inflectional morpheme. These are generally morphemes of the mouth, which through redoubling express the superlative (picture 3 ).

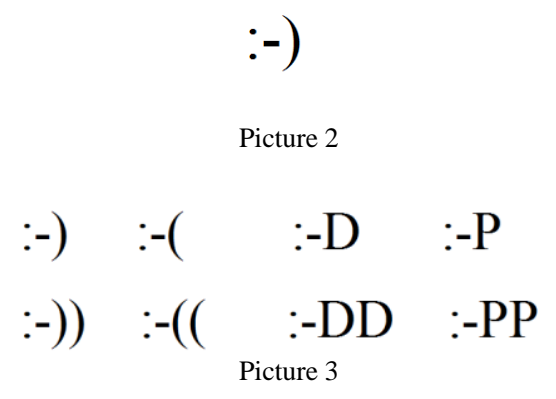

Besides the mouth, reduplication may also be applied to the components as a "tear" and as "saliva".

(1) Ca doit etre super bon :- $)^{\sim \sim 2}$

It looks delicious :- $)^{\sim \sim ~}$,

The repetition of the character cannot be considered as reduplication when it does not reinforce the emotion, but instead completely changes the meaning of the emoticon. Thus, the sign " $8-[]]$ " symbolises opening and closing the mouth (or the jaw twitching), but it cannot be called reduplication.

Interestingly, like words, emoticons can also have reduced forms. Reduction in the emoticon concerns the elements with less semantic function (i.e., not carrying significant information). Obviously, this process is conditioned by the desire of the economy. Usually the most insignificant element of the emoticon is the middle section, which represents the nose. As the image of the nose in most cases is the same and does not carry significant information, it simply is omitted without any changes in the semantics of the emoticon.

Thus, we can conclude that in the structure of emoticons, graphemes with absolutely distinct significance and function become morpheme-like units, which - like word morphemes - can be derivational or inflectional, as well as abbreviated, but never unbound.

\section{B. Classifications}

Typographic emoticons can be classified into two major groups (Table 1):

1. Emotional-attitudinal emoticons that provide emotional information and represent

- Facial expressions

\footnotetext{
${ }^{2}$ The examples are transcribed as they appear in the corpus (with orthographic or typographic errors/adaptations).
} 
- Objects, peoples, animals

- Action

- Appearance

2. Pictorial emoticons are simple pictures made with keyboard characters that do not convey non-verbal information.

\begin{tabular}{|c|c|c|}
\hline \multicolumn{2}{|l|}{ Emotional-attitudinal } & \multirow{5}{*}{ 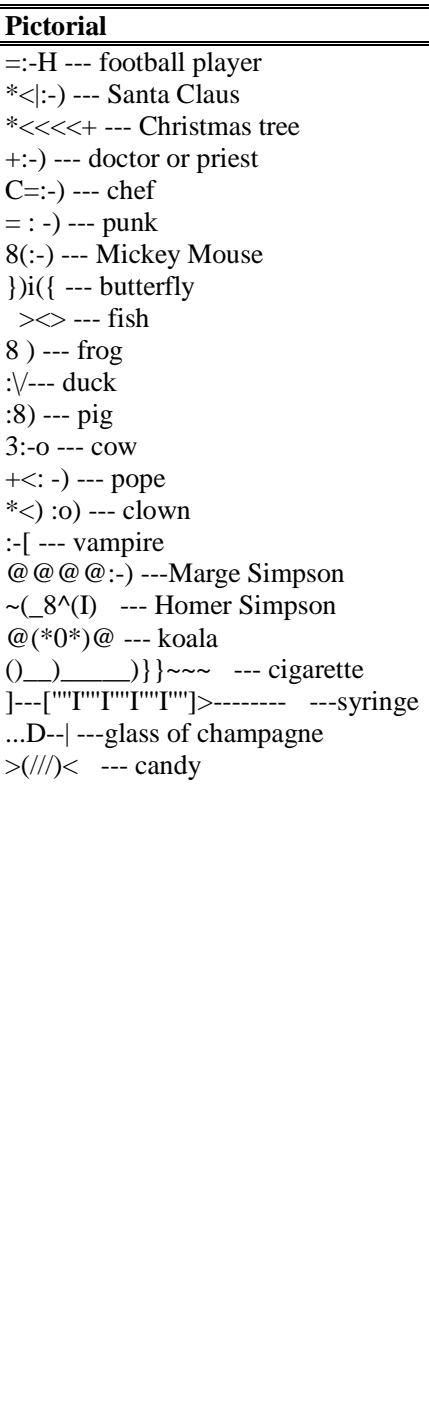 } \\
\hline Facial expressions & 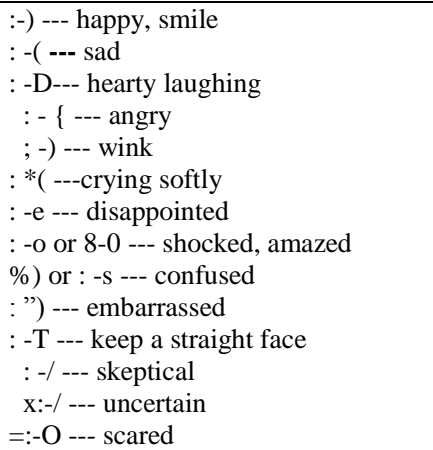 & \\
\hline Objects, peoples, animals & 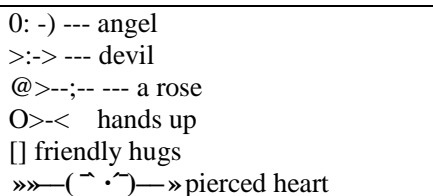 & \\
\hline Action & $\begin{array}{l}:-\mathrm{Q} \text {--- smoking while talking } \\
(((\mathrm{H}))) \text {--- big hug } \\
1 \wedge \mathrm{o} \text {--- yawning or snoring } \\
:--) \text {--- sweating } \\
1-\mathrm{O} \text {--- yawn } \\
:-@ \text {--- screaming } \\
: \mathrm{p} \sim \text {--- drooling } \\
:-* \text {--- kiss } \\
:-? \text {--- smoking a pipe } \\
: \#) \text {--- drunk }\end{array}$ & \\
\hline Appearance & $\begin{array}{l}\text { : o) --- a big nose } \\
(:- \text { ) ---big face } \\
>\%-) \text {--- cross eyed } \\
\{:-) \text {--- hair parted in the middle } \\
\&:-) \text {--- curly hair } \\
8 *) \text {--- glasses and a half mustache } \\
:- \text {-) } \text {--- double chin (or really happy) } \\
:-\}) \text {--- handlebar mustache } \\
\text { B-) --- wearing glasses } \\
:-\{\} \text {--- wearing lipstick } \\
: \%) \% \text {--- a face with acnes } \\
:-\sim) \text {--- got a flowing or running nose } \\
(-:-- \text { - Left handed }\end{array}$ & \\
\hline
\end{tabular}

\section{Use}

Like other non-verbal means, emoticons can also supplement the verbal context as well as express the significance independently. This feature of the graphic sign is very important in written communication, as it simplifies the communication, makes it less ambiguous, and allows part of the semantic information to be transferred from the grammatical form to the separate semantic unit. For example, an unpleasant message can be easily mitigated by putting a smiley at the end. As in speech, sometimes, intonation identifies the intended meaning better than the verbal context, and emoticons can radically alter the meaning of the message. Compare three different answers to the question, Veux-tu aller demain au cinéma avec moi? [Will you go with me to the movies tomorrow?]

- "Non."

- "Non $>$ : /"

- "Non :("

The three convey completely different meanings. The first answer is neutral, however, it could be considered offensive. The second would likely be taken as offensive, because it means, "Leave me alone." Finally, the third implies, "No, unfortunately," and it would therefore come across as more positive.

Alternatively, for example, consider the following answers to the question: Veux-tu m'aider? ['Can you help me?']

- "OK"

- "OK:)" 
- "OK:-/”

- "OK;-)”

The first answer is just a simple statement of fact. The second means, "I am pleased to help." The third implies that the person feels forced to help, while the fourth indicates ambiguity and flirtatiousness.

We can specify two different uses for emoticons: non-verbal and verbal.

Non-verbal emoticons express the para-verbal or non-verbal elements. They are not pronounced, but are expressed through non-verbal devices, such as mime, gesture and intonation.

Some functions of non-verbal emoticons in sentences are as follows:

- Addition of para-verbal elements to the message (when the verbal plane of the text does not contain information about non-verbal elements):

(2) Quand je suis retournée il était déjà chez lui :(

'When I returned, he was already home :( '

Here 'he was already home' can be understood both in a positive and negative sense. The sad emoticon at the end indicates that the message has a negative interpretation. Thus, para-verbal elements help to eliminate misunderstandings while the verbal plane of a message can create it.

\section{- Redundancy}

- Direct denotative correspondence between emoticons and verbal components (when emoticons express the same emotion as the verbal plane):

(3) T'a passe ton exam! :), heureux pr toi! :)

'You have done your examination!:) I'm happy for you!:)) ‘

In the example (3) the first emoticon expresses happiness, which is already clear from the verbal and punctuational plane of the text. The second emoticon also expresses happiness, which, as mentioned, is already expressed with verbal components. Thus, in both cases, the emoticon repeats the verbally expressed emotion.

- Indirect denotative correspondence (when emoticons reinforce or strengthen the significance of verbal components):

(4) Wow! Enfin t'es libre! Heureux pr toi! :)

'Wow! You are free! I'm happy for you!:)) '

Here the emoticon represents tears of joy, which reinforces the emotion expressed verbally while also adding a little humour to the message.

- Antiphrasis (when emoticons are used to contradict or annul the verbally expressed meaning):

(5) Je suis heureuse pour eux :((

'I am happy for them :(( '

(6) tu sais je suis un ange moi $>:($

'I am a real angel you know $>:$ ( '

- Entire turn (when emoticons serve the purpose of an entire message)

(7) - encor mal, po pa aller avc toi. :(

$-:(($

'- I am still ill and can't come with you :(

$-:((c$

- Syntactic marker (often serving as punctuation). The role of intonation and other paralinguistic features in spoken discourse is often decisive in the analysis of the structure of information (Hazaël-Massieux, 1993; Martinet, 1985). As electronic discourse can be considered a 'written oral language' (Anis, 1998), paralinguistic adaptations, especially emoticons, often play the role of syntactic markers.

Consider some examples of different positions emoticons can take in the syntactic chain. Emoticons most often appear at the end of a sentence, either with or in place of standard sentence-final punctuation marks. In this position, emoticons often replace periods and sometimes exclamation marks, but never question marks. Consider the following example:

(8) Merci :) [Place of exclamation mark] D’accord pour 11 h? :-)

'Thanks :) do you agree to meet at 11 ?:-)'

In many cases, emoticons appear in the medial position. An interesting question is whether emoticons in this position are related to other structural markers.

(9) Coucou Jojo:) Ca va? Pourquoi ne m'ecris pas?

'Hi Jojo :) how are you? Why don't you write to me?'

In the example (9), an emoticon with a relatively neutral emotive color is connected to the salutation. It is positioned after the greeting and serves as a politeness indicator. In addition, the emoticon performs the role of punctuation mark, which is absent.

(10) Slt :-(ca va pa bien :((

'Hi :( I am not very well :(('

The example (10) contains a more salient emotive emoticon, ':(,' which is unrelated to the salutation emoticon and expresses disappointment, areal emotion. Therefore, the message has to be understood in the following manner:

1) "Hi" 
2) “:( I am not very well :-((”

The emoticon's function as punctuation is also evident: A smiley in the intermediate position not only marks the end of the first segment but also introduces the second. In the examples cited above, the emoticons serve as single structural markers. However, the message below presents an example of double marking:

(11) moi?:) je l'ai aimee bien.:)

'me? I liked her very much.:) '

In the example (11) the structural function is performed by both emoticons and punctuation marks.

Interestingly enough, the message below (12) starts with a smiley:

(12) :) oui, une bonne soirée. Tu veux voir des photos? Je suis bon photographe tu sais ;)

‘) Yes it was a very cool party. Do you want to view photos? You know I am a good photographer ;)

It is evident that in this case, the smiley presents an emotive answer to a previous message. The smiley is followed by a verbal answer. The sentence ":) Yes, it was very cool." consists of two segments: an emoticon and a verbal message.

Ultimately, we can conclude that in SMS discourse, paralinguistic typography generally consists of para- and nonverbal cues, but at the same time, it can be considered anon-traditional source of information structure.

The verbal use of emoticons is new and less common. It means using an emoticon instead of a word or a phrase. Our research corpus contains only a few examples of verbally used emoticons.

(13) Je t'aime et je veux te :-*)

'I love you and I want you to :-*)' (kiss)

(14) Je te dja di, :-Q e mal pr la sante;)

'I have already told you, ;-Q (smoking) is damaging for the health;)'

In these two examples, emoticons are used as verbs. They can also replace nouns and adjectives.

(15) Voici, c'est por toi :===@,

'Here is for you :===@ ' (a rose)

(16) Je suis tres $>:($

'I am very $>:($ ' (Angry)

Verbally are generally employed graphical pre-designed emoticons. They are animated versions of emoticons that are more sophisticated than the simple combination of keyboard characters and are automatically offered in almost all computer software as a part of instant messaging programs, forums, etc., as well as mobile phones.

\section{CONCLUSIONS}

The popularity of emoticons has increased scientific interest in this new phenomenon. As we saw in the introductory part, studies on emoticons are numerous and adopt different perspectives. Linguistic studies concentrate on analyzing the role of emoticons in the speech-write dichotomy. Therefore, the main objective of our paper was to analyze emoticons as linguistic units and their structure and use in sentences.

Based on the graphic and morphologic analyses of emoticons, we have defined their structure as pictogram-like units formed with alphagrams and topograms that have distinctive and significative functions and visually conditioned relations to their referents.

Based on the research corpus, we have identified two main types of emoticon use, non-verbal and verbal. The first is more frequent, and we describe it in more details in our paper.

Analysis has shown that emoticons are not only paraverbal devices but also structural markers and play a significant role in the formation of sentences.

\section{REFERENCES}

[1] Andrews, Paul. (1994). Put On A Happy Face, But Not In My E-Mail. User Friendly, Seattle Times.

[2] Anis, Jacques. (1988). L'écriture : théories et déscriptions. Avec la coll. de J.-L. Chiss et C. Puech, Bruxelles : De Boeck Université-Wesmael (coll. «Prisme »).

[3] Anis, Jacques. (1998). Texte et ordinateur : l'écriture réinventée, Paris, Bruxelles : De Boeck Université, Coll. Méthodes en sciences humaines.

[4] Azuma, Junichi and Ebner, Martin. (2008). A Stylistic Analysis of Graphic Emoticons: Can they be Candidates for a Universal Visual Language of the Future?, In J. Luca and E. Weippl (Eds.), Proceedings of World Conference on Educational Multimedia, Hypermedia and Telecommunications 2008 (pp. 972-979). Chesapeake, VA: AACE.

[5] Baron, Naomi. (2000). Alphabet to email. How written English evolved and where it's heading. London / New York, Routledge.

[6] Bódi, Zoltan and Veszelszki, Ágnes. (2006). Emoticons [Emotikonok. Érzelemkifejezés az internetes kommunikációban.], Magyar Szemiotikai Társaság, Budapest.

[7] Bunz, Ullia and Campbell, W. Scott. (2004). Politeness accommodation in electronic mail, Communication Research Reports, 21(1), pp.11-25.

[8] Ekman Paul (1977). Facial expression, in Nonverbal bihevior and communication, A. Siegman \& S. Feldstein (eds), New Jersey, Lawrence Elbraum Association.

[9] Fullwood, Chris and Martino, Orsolina, I. (2007). Emoticons and impression formation, Applied Semiotics, volume 19, number 7, pp. 4-14.

[10] Godin, S. (1993). The smiley dictionary. Berkeley, CA: Peachpit. 
[11] Hazaël-Massieux, Marie-Christine. (1993). Ecrire en créole, Oralité et écriture aux Antilles. Paris. L' Harmattan.

[12] Herring, Susan. (2001). Computer-mediated discourse In: D. Schiffrin, D. Tannen \& H. Hamilton (Eds.), The Handbook of Discourse Analysis (pp. 612- 634). Oxford: Blackwell Publishers.

[13] Huffaker, David and Calvert Sandra L. (2005). Gender, Identity and Language Use in Teenage Blogs. Journal of ComputerMediated Communication, 10(2). http://onlinelibrary.wiley.com/doi/10.1111/j.1083-6101.2005.tb00238.x/full (accessed 9/10.2010)

[14] Kruger Justin; Epleye, Nicholas; Parker, Jason; NG, Zhi-Wen. (2005). Egocentrism Over EMail: Can We Communicate as Well as We Think? Journal of Personality and Social Psychology, 89 (6), pp. 925-936.

[15] Marcoccia, Michel. (2000). La représentation du non verbal dans la communication écrite médiatisée par ordinateur, Communication \& Organisation, pp: 265-274.

[16] Marcoccia, Michel and Gauducheau, Nadia. (2007). L'analyse de roles des smileys en production et en récéption : un retour sur la question de l'oralité des écrits numériques, Glottopole, Revue de sociolinguistique en ligne, $\mathrm{n}^{\circ} 10$. juillet. pp. 39-56

[17] Martinet, Andre. 1985). Syntax générale, Paris: Colin (coll. »U»).

[18] Marvin, L. E. (1995). Spoof, spam, lurk and lag: The aesthetics of text-based virtual realities. Journal of Computer-Mediated Communication, 1(2). http://jcmc.indiana.edu/vol1/issue2/marvin.html (accessed 12/11/2010)

[19] Mehrabian, Albert. (1971). Silent Messages. Wadsworth.

[20] Meschtscherjakov, Alexander; Weiss, Astrid and Scherndl, Thomas. (2009). Utilizing emoticons on mobile devices within esm studies to measure emotions in the field (workshop position paper). In MobileHCI09: Proceedings of the 11th International Conference on Human-Computer Interaction with Mobile Devices and Services (supplementary proceedings) (2009).

[21] Mourlhon-Dallies, Florence and Colin, Jean-Yves. (1995). Les rituels énonciatifs des réseaux informatiques entre scientifiques . Les Carnets du Cediscor, 3, pp. 161-172

[22] Pierozak, Isabelle. (2003). Le français tchaté : une étude en trois dimensions - sociolinguistique, syntaxique et graphiqued'usages IRC. Doctoral dissertation, Université d'Aix-Marseille I.

[23] Raymond, Eric S. (1994). The new hacker's dictionary. Cambridge: The MIT Press, pp. 162-163.

[24] Rezabek, L. L., \& Cochenour, J. J. (1998). Visual cues in computer-mediated communication: Supplementing text with emoticons. Journal of Visual Literacy, 18, pp. 201-215.

[25] Sanderson, D. (1993). Smileys. Sebastopol, CA: O’Reilly.

[26] Walther, P. Joseph \& D'Addario P. Kile. (2001). The Impact of Emoticons on Message Interpretation in Computer-Mediated Communication, Social Science Computer Review, 19 (3), pp. 324-347.

[27] Witmer, Diane and Katzman, Sandra Lee. (1997). On-line smiles: Does gender make a difference in the use of graphic accents? Journal of Computer-Mediated Communication, 2(4). http://jcmc.indiana.edu/vol2/issue4/witmer1.html (accessed 10/10/2010)

[28] Wolf, Alecia. (2000). Emotional expression online: Gender difference in emotion use, CyberPsychology \& Behaviors 3(5), 827833.

Natia Amaghlobeli was born in Tbilisi, Georgia, in 1980. Graduated from Tbilisi State University, she has M.A. degree in roman philology. From 2003 to 2006 she was French teacher and researcher at Pedagogical State University of Tbilisi. Has published 4 scientific articles and participated in 4 international conferences. Actually she is doctoral student in Ilia State University and is working on her $\mathrm{PhD}$ thesis about language of French SMS discourse. 